\title{
Synthesis of $\beta-\mathrm{Ca}_{2} \mathrm{P}_{2} \mathrm{O}_{7}$ as an Adsorbent for the Removal of Heavy Metals from Water
}

\author{
Diana Griesiute, Justina Gaidukevic, Aleksej Zarkov (D) and Aivaras Kareiva *(D)
}

Institute of Chemistry, Vilnius University, Naugarduko 24, LT-03225 Vilnius, Lithuania; diana.griesiute@chgf.vu.lt (D.G.); justina.gaidukevic@chf.vu.lt (J.G.); aleksej.zarkov@chf.vu.lt (A.Z.)

* Correspondence: aivaras.kareiva@chgf.vu.lt

Citation: Griesiute, D.; Gaidukevic, J.; Zarkov, A.; Kareiva, A. Synthesis of $\beta-\mathrm{Ca}_{2} \mathrm{P}_{2} \mathrm{O}_{7}$ as an Adsorbent for the Removal of Heavy Metals from Water Sustainability 2021, 13, 7859. https:// doi.org/10.3390/su13147859

Academic Editors: P. Senthil Kumar, Dai-Viet N. Vo, N. Selvaraju and S. Ramalingam

Received: 21 June 2021

Accepted: 11 July 2021

Published: 14 July 2021

Publisher's Note: MDPI stays neutral with regard to jurisdictional claims in published maps and institutional affiliations.

Copyright: (c) 2021 by the authors. Licensee MDPI, Basel, Switzerland. This article is an open access article distributed under the terms and conditions of the Creative Commons Attribution (CC BY) license (https:// creativecommons.org/licenses/by/ $4.0 /)$.

\begin{abstract}
In the present work, beta-calcium pyrophosphate $\left(\beta-\mathrm{Ca}_{2} \mathrm{P}_{2} \mathrm{O}_{7}\right)$ was investigated as a potential adsorbent for the removal of heavy metal ions from water. Single-phase $\beta-\mathrm{Ca}_{2} \mathrm{P}_{2} \mathrm{O}_{7}$ powders were synthesized by a simple, scalable and cost-effective wet precipitation method followed by annealing at $800{ }^{\circ} \mathrm{C}$, which was employed for the conversion of as-precipitated brushite $\left(\mathrm{CaHPO}_{4} \cdot 2 \mathrm{H}_{2} \mathrm{O}\right)$ to $\beta-\mathrm{Ca}_{2} \mathrm{P}_{2} \mathrm{O}_{7}$. Physicochemical properties of the sorbent were characterized by means of X-ray diffraction (XRD) analysis, Fourier transform infrared spectroscopy (FTIR), thermal analysis (TGA/DSC), scanning electron microscopy (SEM) and low temperature adsorption-desorption of nitrogen (BET method). The synthesized powders consisted of porous plate-like particles with micrometer dimensions. Specific surface area calculated by the BET method was found to be $7 \mathrm{~m}^{2} \mathrm{~g}^{-1}$. For the estimation of sorption properties, the aqueous model solutions containing different metal ions ( $\mathrm{Al}^{3+}$, $\mathrm{Cd}^{2+}, \mathrm{Co}^{2+}, \mathrm{Cu}^{2+}, \mathrm{Fe}^{2+}, \mathrm{Mn}^{2+}, \mathrm{Ni}^{2+}, \mathrm{Pb}^{2+}, \mathrm{Sn}^{2+}, \mathrm{Sr}^{2+}$ and $\mathrm{Zn}^{2+}$ ) were used. The adsorption test revealed that $\beta-\mathrm{Ca}_{2} \mathrm{P}_{2} \mathrm{O}_{7}$ demonstrates the highest adsorption capacity for $\mathrm{Pb}^{2+}$ and $\mathrm{Sn}^{2+}$ ions, while the lowest capacity was observed towards $\mathrm{Sr}^{2+}, \mathrm{Ni}^{2+}$ and $\mathrm{Co}^{2+}$ ions. The optimal $\mathrm{pH}$ value for the removal of $\mathrm{Pb}^{2+}$ ions was determined to be 2 , which is also related to the low solubility of $\beta-\mathrm{Ca}_{2} \mathrm{P}_{2} \mathrm{O}_{7}$ at this $\mathrm{pH}$. The adsorption capacity towards $\mathrm{Pb}^{2+}$ ions was calculated as high as $120 \mathrm{mg} \mathrm{g}^{-1}$.
\end{abstract}

Keywords: calcium pyrophosphate; $\mathrm{Ca}_{2} \mathrm{P}_{2} \mathrm{O}_{7}$; wet precipitation; heavy metals; adsorbent

\section{Introduction}

Nowadays, water purification is of essential importance due to the increased contamination, which brings a serious risk to public health and other forms of life on the earth. In order to reduce the contamination, a number of methods and techniques have been employed, including ion exchange, membrane separation, electrolysis, chemical precipitation and adsorption [1,2]. Among these methods, adsorption can be characterized as simple, efficient and low-cost approach. A great variety of sorbents can be employed for water purification, including organic, inorganic and hybrid materials [3]. The successful removal of heavy metals was performed by oxide materials [4], carbon-based materials such as graphene [5] or graphene oxide [6], materials of biological origin [7,8], various composites [9,10], hybrid organic-inorganic materials [11], etc. Nevertheless, the search for and development of new materials for the fast and efficient removal of pollutants from water remains the task of the highest priority.

Calcium phosphates (CPs) are the class of materials that have a huge potential in environmental applications such as water treatment. These materials can be used for the removal of both organic pollutants such as dyes and antibiotics and heavy metal ions [12-15]. The most frequently utilized CP for the application of the removal of heavy metals from water is calcium hydroxyapatite (HAp) [16]. This compound is known very well for its ability to incorporate easily different isovalent and aliovalent ions [17-20]. Its application for the removal of contaminants including heavy metals from different types of waters was demonstrated in numerous works [21-26]. Moreover, sorption capacity 
depends on a number of factors, including morphology, degree of crystallinity and surface area. For instance, Goto and Sasaki developed a synthesis method for the preparation of morphologically controlled HAp and investigated $\mathrm{Sr}^{2+}$ sorption capacity of needleand sponge-shaped HAp powders [27]. It was demonstrated that the morphology and composition of HAp influence a sorption mechanism. In [28], the adsorption performance of HAp with different crystalline and porous structures in multicomponent solutions was investigated.

Moreover, ion-specific sorption is often demonstrated by tested materials [29]. In some particular cases such as technogenic disasters, when a great amount of one type of ion is released into the environment, the adsorbents with ion-specific sorption properties are very important. For example, it is also known that CPs are able to adopt $\mathrm{Sr}^{2+}$ ions, which is a very important property taking into account the radioisotope ${ }^{90} \mathrm{Sr}^{2+}$. This is one of the ions that was released into the environment after the accident at the Fukushima Daiichi nuclear power plant in 2011 [30,31].

Despite the fact that HAp and its sorption properties were extensively studied during the recent decade, the adsorption properties of nonapatitic CPs have not been deeply investigated so far. To the best of our knowledge, there are no reports on the adsorption properties of calcium polyphosphates, namely calcium pyrophosphate $\left(\mathrm{Ca}_{2} \mathrm{P}_{2} \mathrm{O}_{7}\right)$. The aim of this work is to develop a synthesis method for the preparation of $\beta-\mathrm{Ca}_{2} \mathrm{P}_{2} \mathrm{O}_{7}$ and to estimate its adsorption properties towards different metal ions $\left(\mathrm{Al}^{3+}, \mathrm{Cd}^{2+}, \mathrm{Co}^{2+}, \mathrm{Cu}^{2+}\right.$, $\mathrm{Fe}^{2+}, \mathrm{Mn}^{2+}, \mathrm{Ni}^{2+}, \mathrm{Pb}^{2+}, \mathrm{Sn}^{2+}, \mathrm{Sr}^{2+}$ and $\left.\mathrm{Zn}^{2+}\right)$.

\section{Materials and Methods}

\subsection{Synthesis}

$\beta-\mathrm{Ca}_{2} \mathrm{P}_{2} \mathrm{O}_{7}$ powders were synthesized by a simple and cost-effective wet precipitation method using calcium nitrate tetrahydrate $\left(\mathrm{Ca}\left(\mathrm{NO}_{3}\right)_{2} \cdot 4 \mathrm{H}_{2} \mathrm{O}\right.$, Carl Roth, Karlsruhe, Germany, $>99 \%)$ and diammonium hydrogen phosphate $\left(\left(\mathrm{NH}_{4}\right)_{2} \mathrm{HPO}_{4}, \mathrm{Carl}\right.$ Roth, $\left.>98 \%\right)$ as starting materials. For the synthesis, the appropriate amounts of precursors were dissolved in separate beakers in deionized water to obtain $0.80 \mathrm{M}$ solutions. Next, the solution containing phosphate ions was rapidly added to the calcium-containing solution under constant mixing on a magnetic stirrer. Instant formation of white precipitates was observed. The obtained precipitates were aged for 5 min while stirring at 10,000 rpm. Afterward, the precipitates were vacuum filtered, washed with $200 \mathrm{~mL}$ deionized water and dried in the oven at $50{ }^{\circ} \mathrm{C}$ overnight. The $\mathrm{pH}$ value of the solutions was not monitored or additionally adjusted. Dried powders were further annealed in the muffle furnace at different temperatures for $5 \mathrm{~h}$ with a heating rate of $5^{\circ} \mathrm{C} / \mathrm{min}$.

\subsection{Characterization of Synthesis Products}

Thermal decomposition of the as-prepared precipitates was analyzed by thermogravimetric and differential scanning calorimetric (TG-DSC) analysis using Perkin Elmer STA 6000 Simultaneous Thermal Analyzer (Perkin Elmer, Waltham, MA, USA). Dried samples of about $10 \mathrm{mg}$ were heated from 25 to $900{ }^{\circ} \mathrm{C}$ with a heating rate of $10{ }^{\circ} \mathrm{C} / \mathrm{min}$ in dry flowing air $(20 \mathrm{~mL} / \mathrm{min})$. Powder X-ray diffraction (XRD) analysis was performed using $\mathrm{Ni}$-filtered $\mathrm{Cu} \mathrm{K} \alpha$ radiation on a Rigaku MiniFlex II diffractometer working in BraggBrentano $(\theta / 2 \theta)$ geometry. The data were collected within $2 \theta$ range from 10 to $600^{\circ}$ at a step width of $0.02^{\circ}$ and scanning rate of $5^{\circ} / \mathrm{min}$. Fourier transform infrared (FTIR) spectra were taken in the range of $4000-400 \mathrm{~cm}^{-1}$ with a Bruker ALPHA ATR spectrometer with $4 \mathrm{~cm}^{-1}$ resolution. Morphology of the synthesized products was studied with a Hitachi SU-70 field-emission scanning electron microscope (FE-SEM). Quantitative determination of metals was performed using Perkin Elmer Optima 7000DV inductively coupled plasma optical emission spectrometer (ICP-OES). The $\mathrm{N}_{2}$ adsorption and desorption isotherms of samples were obtained at $-196^{\circ} \mathrm{C}$ by using Brunauer-Emmett-Teller (BET) analyzer TriStar II 3020, Micromeritics. Prior to the gas sorption measurements, all the samples were outgassed in $\mathrm{N}_{2}$ atmosphere at $100^{\circ} \mathrm{C}$ for $2 \mathrm{~h}$. 


\subsection{Adsorption Studies}

$\mathrm{Pb}\left(\mathrm{NO}_{3}\right)_{2} \cdot 3 \mathrm{H}_{2} \mathrm{O}$ (Carl Roth, $\left.>99 \%\right), \mathrm{Cu}\left(\mathrm{NO}_{3}\right)_{2} \cdot 3 \mathrm{H}_{2} \mathrm{O}$ (Carl Roth, $\left.>98 \%\right), \mathrm{Ni}\left(\mathrm{NO}_{3}\right)_{2} \cdot 6 \mathrm{H}_{2} \mathrm{O}$ (Carl Roth, $>99 \%$ ), $\mathrm{Cd}\left(\mathrm{NO}_{3}\right)_{2} \cdot 4 \mathrm{H}_{2} \mathrm{O}$ (Sigma-Aldrich, Saint Louis, MO, USA, >98\%), $\mathrm{Zn}\left(\mathrm{NO}_{3}\right)_{2} \cdot 6 \mathrm{H}_{2} \mathrm{O}$ (Carl Roth, $\left.>99 \%\right), \mathrm{Mn}\left(\mathrm{NO}_{3}\right)_{2} \cdot 4 \mathrm{H}_{2} \mathrm{O}$ (Carl Roth, >98\%), $\mathrm{Co}\left(\mathrm{NO}_{3}\right)_{2} \cdot 6 \mathrm{H}_{2} \mathrm{O}$ (Carl Roth, >98\%), $\mathrm{Al}\left(\mathrm{NO}_{3}\right)_{3} \cdot 9 \mathrm{H}_{2} \mathrm{O}$ (Carl Roth, >98\%), $\mathrm{Sr}\left(\mathrm{NO}_{3}\right)_{2}$ (Carl Roth, >99\%), $\mathrm{Ca}\left(\mathrm{NO}_{3}\right)_{2} \cdot 4 \mathrm{H}_{2} \mathrm{O}$ (Carl Roth, $\left.>99 \%\right), \mathrm{FeSO}_{4} \cdot 7 \mathrm{H}_{2} \mathrm{O}$ (Carl Roth, $\left.>99 \%\right)$ and $\mathrm{SnCl}_{2} \cdot 2 \mathrm{H}_{2} \mathrm{O}(\mathrm{Carl}$ Roth, $>98 \%$ ) were used for the preparation of artificial solutions. Laboratory glassware was washed with strong $\mathrm{HNO}_{3}$. For all experiments, Milli-Q water (resistance $18.2 \mathrm{M} \Omega \mathrm{cm}^{-1}$ ) was used. Concentration of metal ions in model solutions was $100 \mathrm{mg} \mathrm{L}^{-1}$ for all metals. For the adsorption experiment, $100 \mathrm{mg}$ of the sorbent were added to $10 \mathrm{~mL}$ of model solution and stirred with a PTFE-coated magnetic bar on a magnetic stirrer in a closed plastic vessel. After that, the sorbent was filtered using a $0.45 \mu \mathrm{m}$ polypropylene syringe filter, and the concentration of metals in treated solutions was measured by ICP-OES. Based on the initial and final (after adsorption experiment) concentrations of metal ions, the removal efficiency was calculated.

\section{Results and Discussion}

The phase crystallinity and purity of as-synthesized powders were characterized by means of XRD analysis. The XRD pattern of as-prepared precipitates is shown in Figure 1a. Evidently, the synthesized powders can be identified as brushite $\left(\mathrm{CaHPO}_{4} \cdot 2 \mathrm{H}_{2} \mathrm{O}\right)$. The positions of the obtained diffraction peaks match very well the standard XRD data of $\mathrm{CaHPO}_{4} \cdot 2 \mathrm{H}_{2} \mathrm{O}$ (ICDD \#00-009-0077) with monoclinic crystal structure and Cc space group (\#9). No reflections corresponding to side phases were obtained. On the other hand, the intensity of the experimental diffraction peaks differs from those in the standard XRD pattern. The reflections raised from 020 crystal planes exhibit higher intensity compared to other reflections, for which the intensity in the experimental pattern is suppressed when compared to the standard XRD data. The observed preferred orientation allows suggesting an anisotropic growth of the crystals, which resulted in the formation of oriented particles. The FTIR spectrum of as-prepared precipitates (Figure 1b) confirms the results obtained by XRD. The obtained absorption bands correspond to brushite, and the shape of the spectrum is in good agreement with that reported in the literature $[32,33]$.
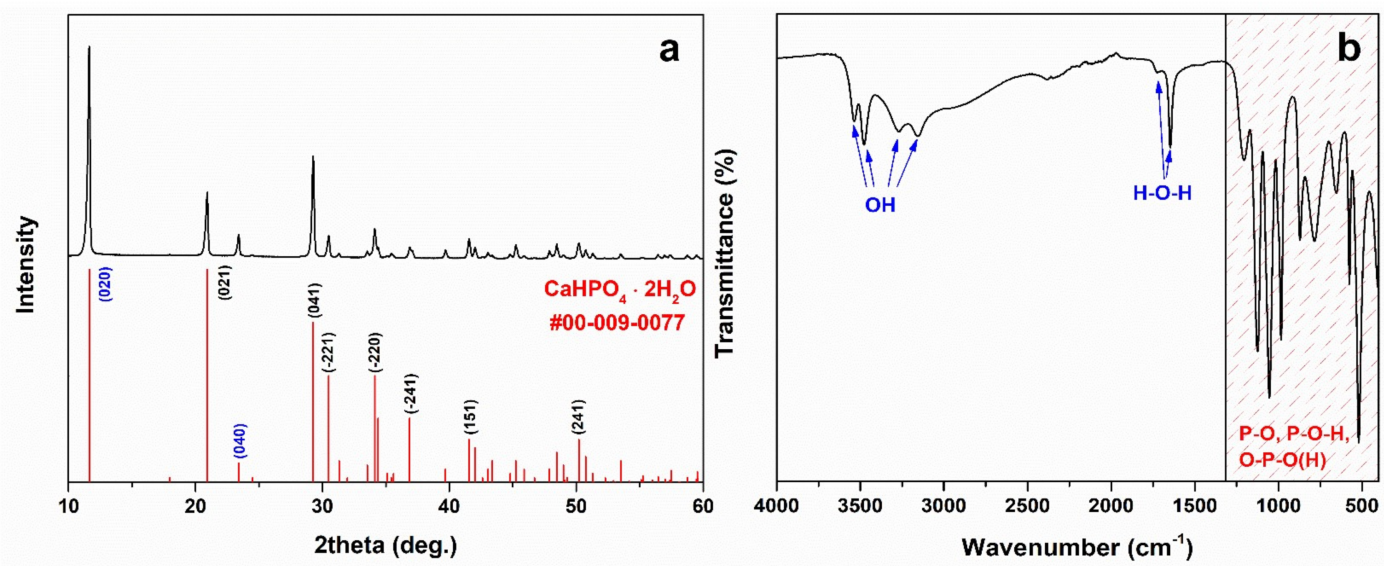

Figure 1. XRD pattern (a) and FTIR spectrum (b) of as-synthesized precipitates.

Thermal decomposition behavior of as-prepared brushite powders was investigated by simultaneous TG/DTG/DSC (thermogravimetry/differential thermogravimetry/differential scanning calorimetry) measurements in order to determine minimal annealing temperature required for the formation of $\beta-\mathrm{Ca}_{2} \mathrm{P}_{2} \mathrm{O}_{7}$. TG/DTG/DSC curves of the as-prepared precipitates are presented in Figure 2. It is evident that thermal decomposition of the obtained specimen occurs in four main steps, which are clearly seen from both TG and DTG curves. The first two mass losses peak at around 140 and $190^{\circ} \mathrm{C}$; both these losses are accompanied 
by endothermic peaks in the DSC curve. The sum weight loss observed for both degradation stages was calculated to be around $20 \%$. These decomposition steps are attributed to the degradation of brushite structure and the release of crystalline water, leading to the formation of monetite $\left(\mathrm{CaHPO}_{4}\right)$ [34]. Theoretically, such transformation should be reflected by $20.9 \%$ mass loss, which is in good agreement with our experimental data. The third and fourth weight losses are observed in the temperature range of $200-460{ }^{\circ} \mathrm{C}$ and centered at ca. $420^{\circ} \mathrm{C}$. This stage is attributed to the degradation of monetite and the formation of $\mathrm{Ca}_{2} \mathrm{P}_{2} \mathrm{O}_{7}[34,35]$. Moreover, the residual mass was determined to be constant at temperatures above $460{ }^{\circ} \mathrm{C}$. Based on the results of thermal analysis, it was concluded that a minimal annealing temperature of $500{ }^{\circ} \mathrm{C}$ is required for the preparation of $\mathrm{Ca}_{2} \mathrm{P}_{2} \mathrm{O}_{7}$.

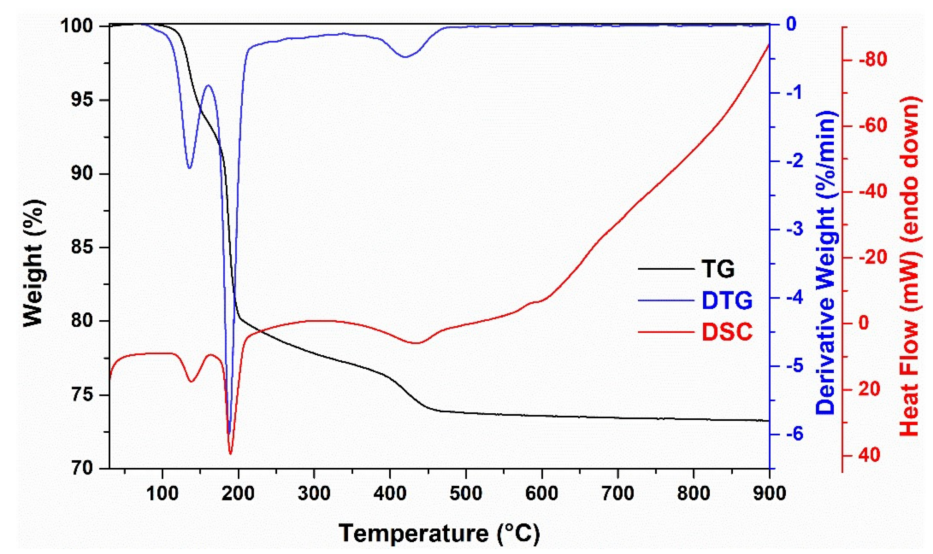

Figure 2. TG/DTG/DSC curves of as-synthesized precipitates.

The XRD patterns of brushite powders annealed at different temperatures are given in Figure 3a. It is clearly seen that after annealing at $500{ }^{\circ} \mathrm{C}$, the compound having $\gamma-\mathrm{Ca}_{2} \mathrm{P}_{2} \mathrm{O}_{7}$ crystal structure was formed. Raising the annealing temperature up to $700{ }^{\circ} \mathrm{C}$ did not result in any phase transformation; however, after the thermal treatment at $800{ }^{\circ} \mathrm{C}$, the $\beta-\mathrm{Ca}_{2} \mathrm{P}_{2} \mathrm{O}_{7}$ polymorph was obtained. All diffraction peaks correspond to $\mathrm{Ca}_{2} \mathrm{P}_{2} \mathrm{O}_{7}$ with tetragonal crystal structure and $\mathrm{P}_{1}$ space group (\#76). It is also seen that the intensity of the diffraction peak corresponding to the 008 plane is significantly higher compared to that of standard XRD data (COD \#99-100-1557), which suggests that the particles remain oriented after the thermal treatment. FTIR spectra of brushite powders annealed at different temperatures (see Figure $3 b$ ) are in good agreement with the results of XRD analysis data. The FTIR spectra of powders annealed in the temperature range from 500 to $700{ }^{\circ} \mathrm{C}$ are identical; however, the shape of the spectrum differs markedly for the sample annealed at $800{ }^{\circ} \mathrm{C}$. The positions of the absorption bands match very well those indicated in the literature [36].
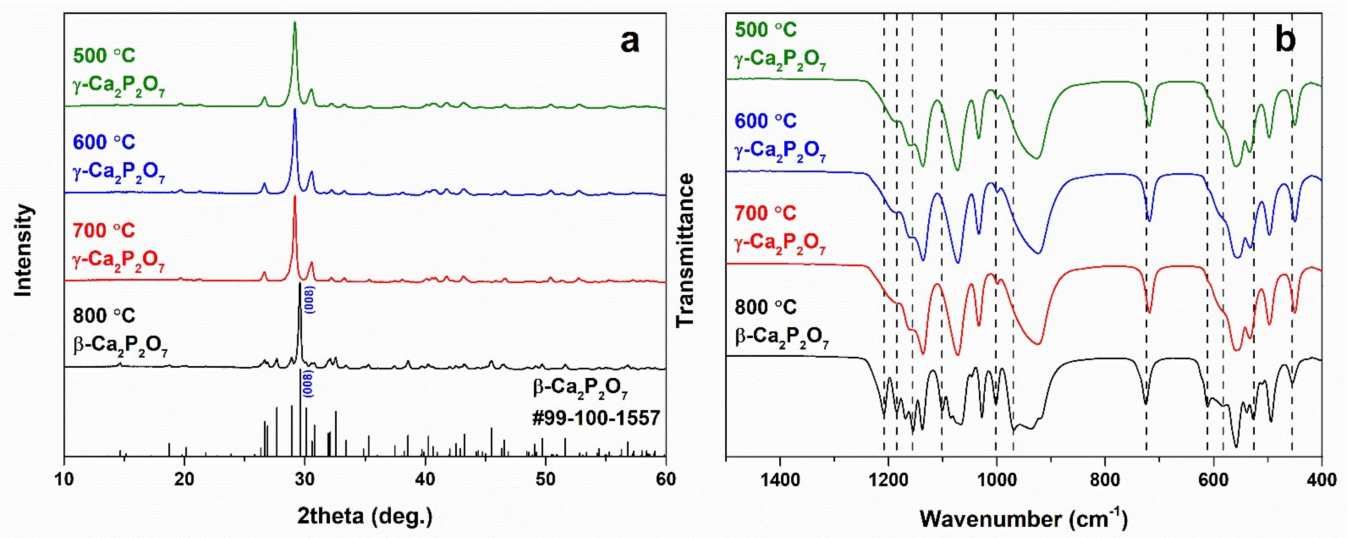

Figure 3. XRD patterns (a) and FTIR spectra (b) of precipitates annealed at different temperatures. 
The morphology of as-prepared and annealed powders was examined using scanning electron microscopy (SEM). The SEM micrographs of as-precipitated and annealed powders are demonstrated in Figure 4. It is seen that as-prepared brushite powders (Figure 4a) consist of plate-like particles, which are stacked on each other. This observation is in agreement with the results of the XRD analysis, which revealed a preferred orientation of the sample (Figure 1a). The obtained particles possess micrometer dimensions by length with a thickness in the sub-micrometer scale. SEM images of powders annealed at $800{ }^{\circ} \mathrm{C}$ taken at different magnifications are shown in Figure $4 \mathrm{~b}-\mathrm{d}$. Obviously, a thermally induced phase transition from brushite to $\beta-\mathrm{Ca}_{2} \mathrm{P}_{2} \mathrm{O}_{7}$ took place without the destruction of the plate-like morphology of the powders, which is also seen in the annealed sample. On the other hand, the annealing procedure resulted in the formation of porosity, which could be a beneficial feature in terms of surface area and adsorption of foreign ions [37].
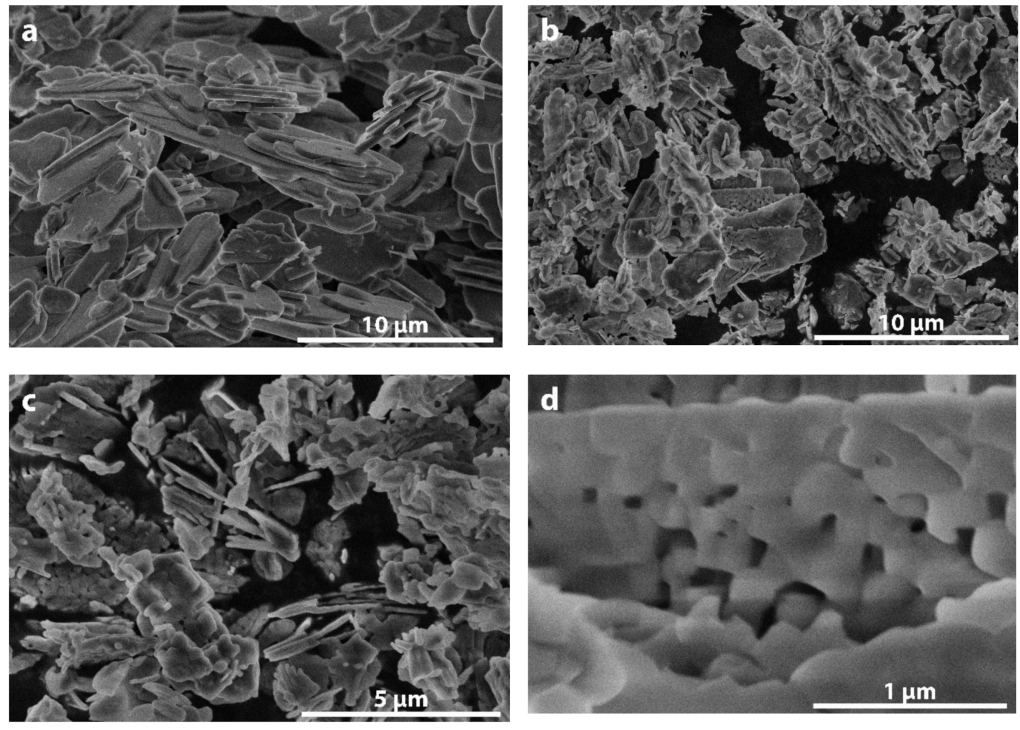

Figure 4. SEM images of as-synthesized precipitates (a) and precipitates annealed at $800{ }^{\circ} \mathrm{C}(\mathbf{b}-\mathbf{d})$.

The $\mathrm{N}_{2}$ adsorption-desorption isotherm for the $\beta-\mathrm{Ca}_{2} \mathrm{P}_{2} \mathrm{O}_{7}$ annealed at $800{ }^{\circ} \mathrm{C}$ was measured in order to estimate the surface area and porosity of the material. The results of the textural analysis are presented in Figure 5 showing the $\mathrm{N}_{2}$ adsorption-desorption isotherm and the corresponding pore size distribution curve. According to the IUPAC classification, the $\mathrm{N}_{2}$ adsorption-desorption isotherm of the sample was type IV with a hysteresis loop type H3 [38]. Type IV adsorption-desorption isotherm suggests the presence of mesopores, while type $\mathrm{H} 3$ hysteresis loop is related with aggregates of plate-like particles with slit-shaped pores. These results are in good agreement with surface morphological observations seen in SEM micrographs (Figure 4). The pore size distribution curve (inset of Figure 5) shows that powders are characterized by a monomodal mesoporosity with well-developed mesopores centered at approximately $50 \mathrm{~nm}$. The powders have a relatively wide distribution of pores ranging from 6.5 to $120 \mathrm{~nm}$. The external surface area, which is corresponding to the mesopore surface area, was determined to be $4 \mathrm{~m}^{2} \mathrm{~g}^{-1}$, and the specific surface area calculated by the BET method was found to be $7 \mathrm{~m}^{2} \mathrm{~g}^{-1}$.

The initial assessment of the sorption properties of $\beta-\mathrm{Ca}_{2} \mathrm{P}_{2} \mathrm{O}_{7}$ powders was performed with single-element model solutions. The removal efficiency calculated for different ions is demonstrated in Figure 6. The highest efficiencies were achieved for $\mathrm{Pb}^{2+}$ and $\mathrm{Sn}^{2+}$ ions and reached 99.9 and $66.1 \%$, respectively. On the other hand, the lowest values were observed for $\mathrm{Sr}^{2+}, \mathrm{Ni}^{2+}, \mathrm{Mn}^{2+}$ and $\mathrm{Co}^{2+}$, which were determined to be below $10 \%$. From the first look, such a selective absorption of $\mathrm{Pb}^{2+}$ and $\mathrm{Sn}^{2+}$ could be ascribed to the size effect, since these ions are relatively large; however, such explanation is unsuitable for $\mathrm{Sr}^{2+}$, which is also large. Other calcium phosphates such as HAp are known very well for the 
$\mathrm{Sr}^{2+}$ adsorption capacity [28]; nevertheless, $\beta-\mathrm{Ca}_{2} \mathrm{P}_{2} \mathrm{O}_{7}$ did not demonstrate an efficient removal of $\mathrm{Sr}^{2+}$ ions. Taking into account the results presented in Figure 6, it was decided to perform further experiments with $\mathrm{Pb}^{2+}$ ions.

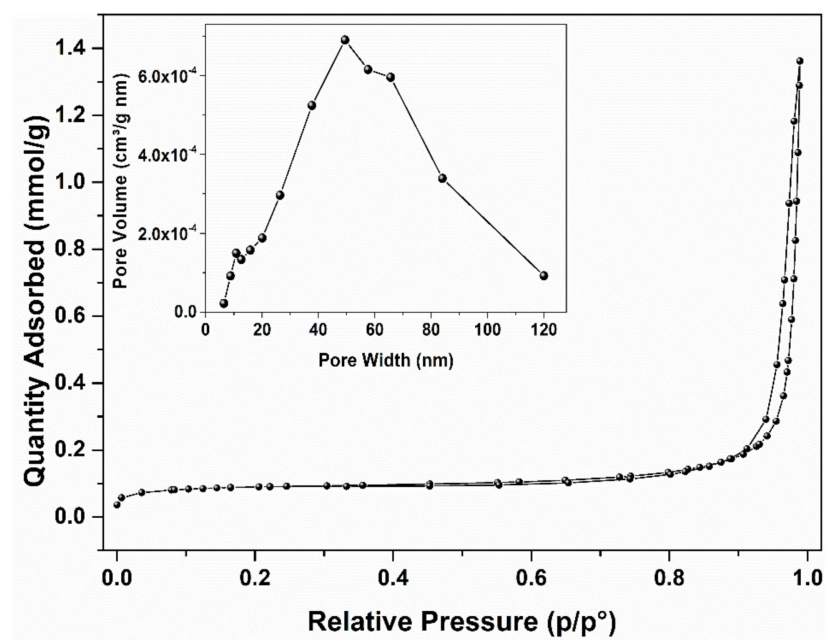

Figure 5. $\mathrm{N}_{2}$ adsorption-desorption isotherm of $\beta-\mathrm{Ca}_{2} \mathrm{P}_{2} \mathrm{O}_{7}$ annealed at $800{ }^{\circ} \mathrm{C}$. In the insert is presented the pore size distribution curve.

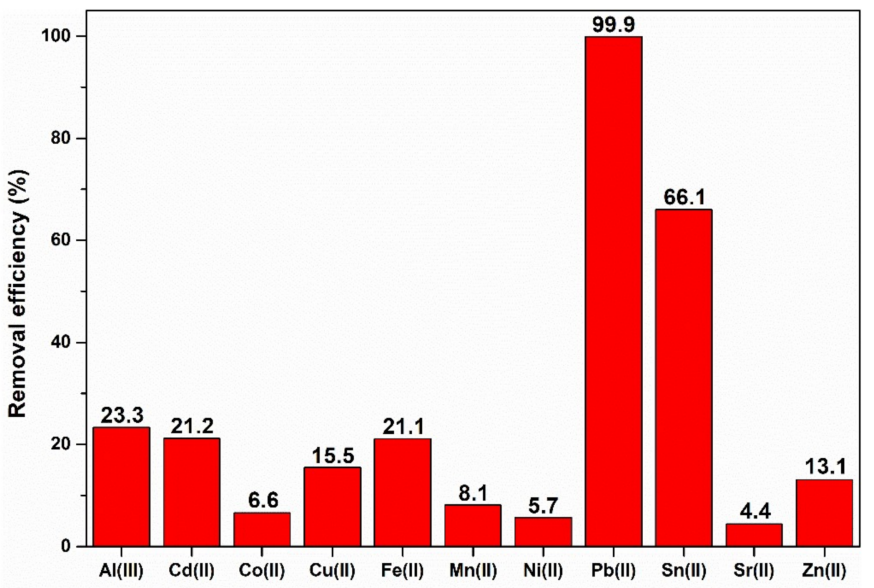

Figure 6. Removal efficiency for different metal ions. Contact time $-5 \mathrm{~h}$, dose of sorbent $-10 \mathrm{~g} \mathrm{~L}^{-1}$.

In the next step, the influence of medium $\mathrm{pH}$ on the efficiency of removal of $\mathrm{Pb}^{2+}$ ions was investigated. Taking into account the chemical properties of $\beta-\mathrm{Ca}_{2} \mathrm{P}_{2} \mathrm{O}_{7}$, namely its solubility at low $\mathrm{pH}$ values, it was decided additionally to monitor the concentration of $\mathrm{P}$ ions in investigated solutions. The dependence of removal efficiency and concentration of dissolved $\mathrm{P}$ amount, recalculated to the dissolved part of $\beta-\mathrm{Ca}_{2} \mathrm{P}_{2} \mathrm{O}_{7}$, on medium $\mathrm{pH}$ in the range from 1 to 6 are demonstrated in Figure $7 \mathrm{a}$. The highest removal efficiency $(97.7 \%)$ was achieved at $\mathrm{pH} 2$; at the same time, the solubility of $\beta-\mathrm{Ca}_{2} \mathrm{P}_{2} \mathrm{O}_{7}$ at this $\mathrm{pH}$ value is insignificant. At lower $\mathrm{pH}$, the removal efficiency is rather comparable; however, a drastic increase in the solubility of the sorbent was observed. In the $\mathrm{pH}$ range from 3 to 6 , the removal efficiency varies in the range from 32 to $22 \%$. The concentration of $\mathrm{P}$ determined in the aqueous medium was negligible, indicating the low solubility of $\beta-\mathrm{Ca}_{2} \mathrm{P}_{2} \mathrm{O}_{7}$ in this $\mathrm{pH}$ range. These results allow suggesting that the adsorption mechanism is at least partially related to the dissolution-precipitation process. The dependence of $\mathrm{Pb}^{2+}$ removal efficiency on contact time is depicted in Figure $7 \mathrm{~b}$. It is seen that removal efficiency increases nearly linearly in the range from 0 to $60 \mathrm{~min}$ when the equilibrium is achieved. 

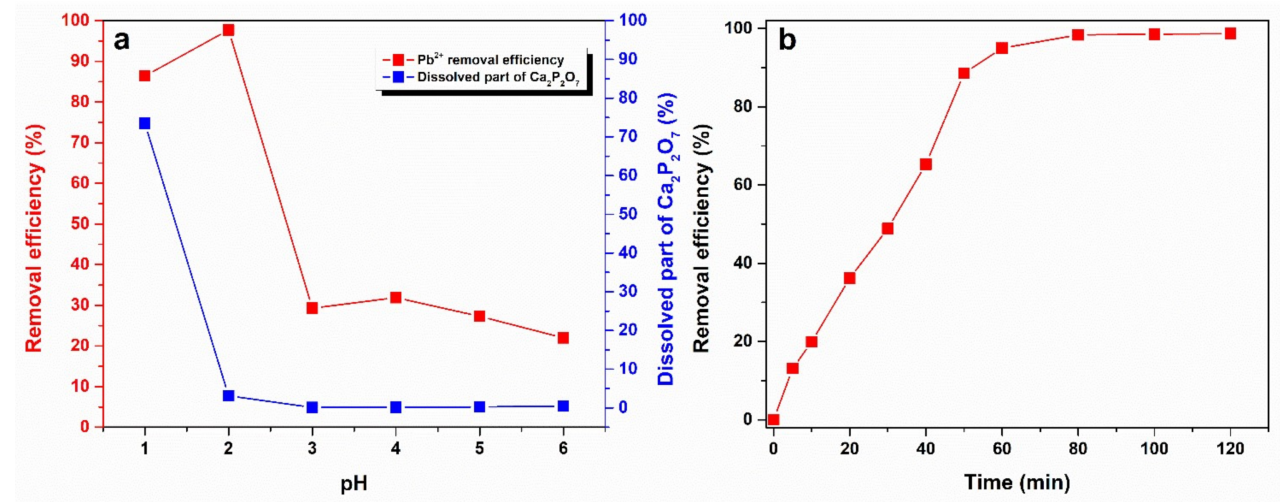

Figure 7. Removal efficiency of $\mathrm{Pb}^{2+}$ and dissolution of $\beta-\mathrm{Ca}_{2} \mathrm{P}_{2} \mathrm{O}_{7}$ at different initial $\mathrm{pH}$ values. Contact time- $1 \mathrm{~h}$, dose of sorbent $-5 \mathrm{~g} / \mathrm{L}$ (a). Dependence of $\mathrm{Pb}^{2+}$ removal efficiency on contact time, dose of sorbent $5 \mathrm{~g} \mathrm{~L}^{-1}$, $\mathrm{pH}$ of solution was $2.0(\mathbf{b})$.

Based on the obtained results, the adsorption capacitance towards $\mathrm{Pb}^{2+}$ ions was calculated as high as $120 \mathrm{mg} \mathrm{g}^{-1}$. This value is comparable with those of some sorbents studied for $\mathrm{Pb}^{2+}$ ion removal. For instance, acidified multiwalled carbon nanotubes demonstrated the adsorption capacity of $91 \mathrm{mg} \mathrm{g}^{-1}$, whereas nonacidified multiwalled carbon nanotubes only demonstrated the adsorption capacity of $7.2 \mathrm{mg} \mathrm{g}^{-1}$ [39]. Pinecone activated carbon showed the capacity of only $27.5 \mathrm{mg} \mathrm{g}^{-1}$ [40]. Natural phosphate was characterized by an adsorption capacity of $115 \mathrm{mg} \mathrm{g}^{-1}$ [41]. On the other hand, our obtained capacity value for $\beta-\mathrm{Ca}_{2} \mathrm{P}_{2} \mathrm{O}_{7}$ is significantly lower than that demonstrated by nanohydroxyapatite, which was reported to have an adsorption capacity of $1000 \mathrm{mg} \mathrm{g}^{-1}$ [42]. Nevertheless, it was demonstrated that $\beta-\mathrm{Ca}_{2} \mathrm{P}_{2} \mathrm{O}_{7}$ is potentially suitable for the removal of some heavy metals from water. Further steps towards increasing removal efficiency could be directed towards the increase in surface area and porosity and the reduction in particle size to the nanoscale.

\section{Conclusions}

In the present work, single-phase $\beta-\mathrm{Ca}_{2} \mathrm{P}_{2} \mathrm{O}_{7}$ was synthesized by a wet precipitation process followed by thermal treatment at $800{ }^{\circ} \mathrm{C}$. The obtained material consisted of porous plate-like particles with micrometer dimensions. The external surface area, which corresponds to the mesoporous surface area, was determined to be $4 \mathrm{~m}^{2} \mathrm{~g}^{-1}$, and the specific surface area calculated by the BET method was determined to be $7 \mathrm{~m}^{2} \mathrm{~g}^{-1}$. The sorption properties of the obtained material were studied for different metal ions in model aqueous solutions. It was determined that $\beta-\mathrm{Ca}_{2} \mathrm{P}_{2} \mathrm{O}_{7}$ demonstrates the highest adsorption capacity for $\mathrm{Pb}^{2+}$ and $\mathrm{Sn}^{2+}$ ions, while the lowest capacities were observed towards $\mathrm{Sr}^{2+}$, $\mathrm{Ni}^{2+}$ and $\mathrm{Co}^{2+}$ ions. The optimal $\mathrm{pH}$ value for the removal of $\mathrm{Pb}^{2+}$ ions was determined to be 2 , which is related to the low solubility of $\beta-\mathrm{Ca}_{2} \mathrm{P}_{2} \mathrm{O}_{7}$ at this $\mathrm{pH}$. The adsorption capacity towards $\mathrm{Pb}^{2+}$ ions was calculated as high as $120 \mathrm{mg} \mathrm{g}^{-1}$.

Author Contributions: Conceptualization, A.Z. and A.K.; methodology, A.Z.; formal analysis, D.G., J.G. and A.Z.; investigation, D.G., J.G. and A.Z.; resources, A.K.; writing—original draft preparation, D.G.; writing-review and editing, A.K.; visualization, D.G.; supervision, A.Z. All authors have read and agreed to the published version of the manuscript.

Funding: This project has received funding from European Social Fund (project No. 09.3.3-LMT-K712-19-0069) under grant agreement with the Research Council of Lithuania (LMTLT).

Institutional Review Board Statement: Not applicable.

Informed Consent Statement: Not applicable.

Data Availability Statement: Data is contained within the article.

Acknowledgments: Authors would like to thank Matas Grigaliunas for technical assistance.

Conflicts of Interest: The authors declare no conflict of interest. 


\section{References}

1. Ivanets, A.I.; Kitikova, N.V.; Shashkova, I.L.; Oleksiienko, O.V.; Levchuk, I.; Sillanpää, M. Removal of $\mathrm{Zn}^{2+}, \mathrm{Fe}^{2+}, \mathrm{Cu}^{2+}, \mathrm{Pb}^{2+}$, $\mathrm{Cd}^{2+}, \mathrm{Ni}^{2+}$ and $\mathrm{Co}^{2+}$ ions from aqueous solutions using modified phosphate dolomite. J. Environ. Chem. Eng. 2014, 2, 981-987. [CrossRef]

2. Theerthagiri, J.; Lee, S.J.; Karuppasamy, K.; Arulmani, S.; Veeralakshmi, S.; Ashokkumar, M.; Choi, M.Y. Application of advanced materials in sonophotocatalytic processes for the remediation of environmental pollutants. J. Hazard. Mater. 2021, $412,125245$. [CrossRef]

3. Singh, S.; Wasewar, K.L.; Kansal, S.K. Low-cost adsorbents for removal of inorganic impurities from wastewater. In Inorganic Pollutants in Water; Devi, P., Singh, P., Kansal, S.K., Eds.; Elsevier: Amsterdam, The Netherlands, 2020; pp. 173-203. [CrossRef]

4. Kondo, Y.; Goto, T.; Sekino, T. Sorption capacity of seaweed-like sodium titanate mats for $\mathrm{Co}^{2+}$ removal. RSC Adv. 2020, 10, 41032-41040. [CrossRef]

5. Ahmad, S.Z.N.; Wan Salleh, W.N.; Ismail, A.F.; Yusof, N.; Mohd Yusop, M.Z.; Aziz, F. Adsorptive removal of heavy metal ions using graphene-based nanomaterials: Toxicity, roles of functional groups and mechanisms. Chemosphere 2020, $248,126008$. [CrossRef]

6. Yao, N.; Li, C.; Yu, J.; Xu, Q.; Wei, S.; Tian, Z.; Yang, Z.; Yang, W.; Shen, J. Insight into adsorption of combined antibiotic-heavy metal contaminants on graphene oxide in water. Sep. Purif. Technol. 2020, 236, 116278. [CrossRef]

7. Novoseltseva, V.; Yankovych, H.; Kovalenko, O.; Vaclavikova, M.; Melnyk, I. Production of high-performance lead(II) ions adsorbents from pea peels waste as a sustainable resource. Waste Manag. Res. 2021, 39, 584-593. [CrossRef] [PubMed]

8. El-Amier, Y.A.; Elsayed, A.; El-Esawi, M.A.; Noureldeen, A.; Darwish, H.; Fakhry, H. Optimizing the Biosorption Behavior of Ludwigia stolonifera in the Removal of Lead and Chromium Metal Ions from Synthetic Wastewater. Sustainability 2021, 13, 6390. [CrossRef]

9. Pelalak, R.; Heidari, Z.; Khatami, S.M.; Kurniawan, T.A.; Marjani, A.; Shirazian, S. Oak wood ash $/ \mathrm{GO} / \mathrm{Fe}_{3} \mathrm{O}_{4}$ adsorption efficiencies for cadmium and lead removal from aqueous solution: Kinetics, equilibrium and thermodynamic evaluation. Arab. $J$ Chem. 2021, 14, 102991. [CrossRef]

10. Iqbal, T.; Iqbal, S.; Batool, F.; Thomas, D.; Iqbal, M.M.H. Utilization of a Newly Developed Nanomaterial Based on Loading of Biochar with Hematite for the Removal of Cadmium Ions from Aqueous Media. Sustainability 2021, 13, 2191. [CrossRef]

11. Melnyk, I.V.; Pogorilyi, R.P.; Zub, Y.L.; Vaclavikova, M.; Gdula, K.; Dabrowski, A.; Seisenbaeva, G.A.; Kessler, V.G. Protection of Thiol Groups on the Surface of Magnetic Adsorbents and Their Application for Wastewater Treatment. Sci. Rep. $2018,8,13$. [CrossRef]

12. Ahmed, M.K.; Mansour, S.F.; Ramadan, R.; Afifi, M.; Mostafa, M.S.; El-dek, S.I.; Uskoković, V. Tuning the composition of new brushite/vivianite mixed systems for superior heavy metal removal efficiency from contaminated waters. J. Water Process Eng. 2020, 34, 101090. [CrossRef]

13. Hoang, T.T.T.L.; Unob, F.; Suvokhiaw, S.; Sukpirom, N. One-pot synthesis of amorphous calcium phosphate $/ \mathrm{Fe}_{3} \mathrm{O}_{4}$ composites and the application in the removal of cadmium. J. Environ. Chem. Eng. 2020, 8, 103653. [CrossRef]

14. Goto, T.; Cho, S.H.; Ohtsuki, C.; Sekino, T. Selective adsorption of dyes on $\mathrm{TiO}_{2}$-modified hydroxyapatite photocatalysts morphologically controlled by solvothermal synthesis. J. Environ. Chem. Eng. 2021, 9, 105738. [CrossRef]

15. Zhu, J.; Shu, J.; Yue, X.; Su, Y. Hollow and porous octacalcium phosphate superstructures mediated by the polyelectrolyte PSS: A superior removal capacity for heavy metal and antibiotics. J. Mater. Sci. 2020, 55, 7502-7517. [CrossRef]

16. Hernández-Cocoletzi, H.; Salinas, R.A.; Águila-Almanza, E.; Rubio-Rosas, E.; Chai, W.S.; Chew, K.W.; Mariscal-Hernández, C.; Show, P.L. Natural hydroxyapatite from fishbone waste for the rapid adsorption of heavy metals of aqueous effluent. Environ. Technol. Innov. 2020, 20, 101109. [CrossRef]

17. Šupová, M. Substituted hydroxyapatites for biomedical applications: A review. Ceram. Int. 2015, 41, 9203-9231. [CrossRef]

18. Ishikawa, K.; Garskaite, E.; Kareiva, A. Sol-gel synthesis of calcium phosphate-based biomaterials-A review of environmentally benign, simple and effective synthesis routes. J. Sol-Gel Sci. Technol. 2020, 94, 551-572. [CrossRef]

19. Sinusaite, L.; Popov, A.; Antuzevics, A.; Mažeika, K.; Baltrunas, D.; Yang, J.-C.; Horng, J.-L.; Shi, S.; Sekino, T.; Ishikawa, K.; et al. Fe and Zn co-substituted beta-tricalcium phosphate ( $\beta$-TCP): Synthesis, structural, magnetic, mechanical and biological properties. Mater. Sci. Eng. C 2020, 112, 110918. [CrossRef]

20. Sinusaite, L.; Kareiva, A.; Zarkov, A. Thermally induced crystallization and phase evolution of amorphous calcium phosphate substituted with divalent cations having different size. Cryst. Growth Des. 2021, 21, 1242-1248. [CrossRef]

21. Hamad, A.A.; Hassouna, M.S.; Shalaby, T.I.; Elkady, M.F.; Abd Elkawi, M.A.; Hamad, H.A. Electrospun cellulose acetate nanofiber incorporated with hydroxyapatite for removal of heavy metals. Int. J. Biol. Macromol. 2020, 151, 1299-1313. [CrossRef]

22. Pai, S.; Kini, S.M.; Selvaraj, R.; Pugazhendhi, A. A review on the synthesis of hydroxyapatite, its composites and adsorptive removal of pollutants from wastewater. J. Water Process Eng. 2020, 38, 101574. [CrossRef]

23. Ma, K.; Cui, H.; Zhou, A.; Wu, H.; Dong, X.; Zu, F.; Yi, J.; Wang, R.; Xu, Q. Mesoporous hydroxyapatite: Synthesis in molecular self-assembly and adsorption properties. Microporous Mesoporous Mater. 2021, 323, 111164. [CrossRef]

24. Nayak, A.; Bhushan, B. Hydroxyapatite as an advanced adsorbent for removal of heavy metal ions from water: Focus on its applications and limitations. Mater. Today Proc. 2021. [CrossRef] 
25. Ayodele, O.; Olusegun, S.J.; Oluwasina, O.O.; Okoronkwo, E.A.; Olanipekun, E.O.; Mohallem, N.D.S.; Guimarães, W.G.; Gomes, B.L.F.d.M.; Souza, G.d.O.; Duarte, H.A. Experimental and theoretical studies of the adsorption of $\mathrm{Cu}$ and Ni ions from wastewater by hydroxyapatite derived from eggshells. Environ. Nanotechnol. Monit. Manag. 2021, 15, 100439. [CrossRef]

26. Tran, T.N.; Kim, J.; Park, J.-S.; Chung, Y.; Han, J.; Oh, S.; Kang, S. Novel Hydroxyapatite Beads for the Adsorption of Radionuclides from Decommissioned Nuclear Power Plant Sites. Appl. Sci. 2021, 11, 1746. [CrossRef]

27. Goto, T.; Sasaki, K. Synthesis of morphologically controlled hydroxyapatite from fish bone by urea-assisted hydrothermal treatment and its $\mathrm{Sr}^{2+}$ sorption capacity. Powder Technol. 2016, 292, 314-322. [CrossRef]

28. Ivanets, A.I.; Kitikova, N.V.; Shashkova, I.L.; Roshchina, M.Y.; Srivastava, V.; Sillanpää, M. Adsorption performance of hydroxyapatite with different crystalline and porous structure towards metal ions in multicomponent solution. J. Water Process Eng. 2019, 32, 100963. [CrossRef]

29. Sekine, Y.; Motokawa, R.; Kozai, N.; Ohnuki, T.; Matsumura, D.; Tsuji, T.; Kawasaki, R.; Akiyoshi, K. Calcium-deficient Hydroxyapatite as a Potential Sorbent for Strontium. Sci. Rep. 2017, 7, 2064. [CrossRef] [PubMed]

30. Steinhauser, G.; Schauer, V.; Shozugawa, K. Concentration of Strontium-90 at Selected Hot Spots in Japan. PLoS ONE 2013, 8, e57760. [CrossRef]

31. Koarai, K.; Kino, Y.; Takahashi, A.; Suzuki, T.; Shimizu, Y.; Chiba, M.; Osaka, K.; Sasaki, K.; Fukuda, T.; Isogai, E.; et al. ${ }^{90}$ Sr in teeth of cattle abandoned in evacuation zone: Record of pollution from the Fukushima-Daiichi Nuclear Power Plant accident. Sci. Rep. 2016, 6, 24077. [CrossRef]

32. Boanini, E.; Silingardi, F.; Gazzano, M.; Bigi, A. Synthesis and Hydrolysis of Brushite (DCPD): The Role of Ionic Substitution. Cryst. Growth Des. 2021, 21, 1689-1697. [CrossRef]

33. Tortet, L.; Gavarri, J.R.; Nihoul, G.; Dianoux, A.J. Study of Protonic Mobility in $\mathrm{CaHPO}_{4} \cdot 2 \mathrm{H}_{2} \mathrm{O}$ (Brushite) and CaHPO $(\mathrm{Monetite)}$ by Infrared Spectroscopy and Neutron Scattering. J. Solid State Chem. 1997, 132, 6-16. [CrossRef]

34. Tas, A.C.; Bhaduri, S.B. Chemical Processing of CaHPO4 $2 \mathrm{H}_{2}$ O. J. Am. Ceram. Soc. 2004, 87, 2195-2200. [CrossRef]

35. Bolarinwa, A.; Gbureck, U.; Purnell, P.; Bold, M.; Grover, L.M. Cement casting of calcium pyrophosphate based bioceramics. Adv. Appl. Ceram. 2010, 109, 291-295. [CrossRef]

36. Fowler, B.O.; Moreno, E.C.; Brown, W.E. Infra-red spectra of hydroxyapatite, octacalcium phosphate and pyrolysed octacalcium phosphate. Arch. Oral Biol. 1966, 11, 477-492. [CrossRef]

37. Valeikiene, L.; Grigoraviciute-Puroniene, I.; Kareiva, A. Alkaline earth metal substitution effects in sol-gel derived mixed-metal oxides and $\mathrm{Mg}_{2-\mathrm{x}} \mathrm{M}_{\mathrm{x}} / \mathrm{Al}_{1}(\mathrm{M}=\mathrm{Ca}, \mathrm{Sr}, \mathrm{Ba})$-layered double hydroxides. J. Aust. Ceram. Soc. 2020, 56, 1531-1541. [CrossRef]

38. Sing, K.S.W. Reporting physisorption data for gas/solid systems with special reference to the determination of surface area and porosity (Recommendations 1984). Pure Appl. Chem. 1985, 57, 603-619. [CrossRef]

39. Wang, H.; Zhou, A.; Peng, F.; Yu, H.; Yang, J. Mechanism study on adsorption of acidified multiwalled carbon nanotubes to Pb(II). J. Colloid Interface Sci. 2007, 316, 277-283. [CrossRef]

40. Momčilović, M.; Purenović, M.; Bojić, A.; Zarubica, A.; Ranđelović, M. Removal of lead(II) ions from aqueous solutions by adsorption onto pine cone activated carbon. Desalination 2011, 276, 53-59. [CrossRef]

41. Mouflih, M.; Aklil, A.; Sebti, S. Removal of lead from aqueous solutions by activated phosphate. J. Hazard. Mater. 2005, 119, 183-188. [CrossRef]

42. Mobasherpour, I.; Salahi, E.; Pazouki, M. Comparative of the removal of $\mathrm{Pb}^{2+}, \mathrm{Cd}^{2+}$ and $\mathrm{Ni}^{2+}$ by nano crystallite hydroxyapatite from aqueous solutions: Adsorption isotherm study. Arab. J. Chem. 2012, 5, 439-446. [CrossRef] 